\title{
Coping Styles and Depression among Patients with Solid Organ Cancers Attending Two Tertiary Care Hospitals of Karachi: A Cross Sectional Study
}

\author{
Khadija Vadsaria $^{1 *}$, Adnan Jabbar ${ }^{2}$, Iqbal Azam¹, Sameera Rizvi', Ghulam Haider ${ }^{3}$, Haider Naqvi ${ }^{4}$ \\ ${ }^{1}$ Department of Community Health Sciences, Aga Khan University, Karachi, Pakistan \\ ${ }^{2}$ Department of Oncology, Aga Khan University, Karachi, Pakistan \\ ${ }^{3}$ Department of Clinical Oncology, Jinnah Post Graduate Medical Centre, Karachi, Pakistan \\ ${ }^{4}$ Psychiatry Department, Ziauddin University, Karachi, Pakistan \\ Email:^Khadija.vadsaria@gmail.com, adnan.jabbar@aku.edu,iqbal.azam@aku.edu,ar_sameera@yahoo.com, \\ dr_ghaider1@yahoo.com, haideralinaqvi9@gmail.com
}

\begin{abstract}
How to cite this paper: Vadsaria, K., Jabbar, A., Azam, I., Rizvi, S., Haider, G. and Naqvi, H. (2017) Coping Styles and Depression among Patients with Solid Organ Cancers Attending Two Tertiary Care Hospitals of Karachi: A Cross Sectional Study. Open Journal of Epidemiology, 7, 69-83. https://doi.org/10.4236/ojepi.2017.71007
\end{abstract}

Received: January 13, 2017

Accepted: February 12, 2017

Published: February 15, 2017

Copyright $\odot 2017$ by authors and Scientific Research Publishing Inc. This work is licensed under the Creative Commons Attribution International License (CC BY 4.0).

http://creativecommons.org/licenses/by/4.0/

\begin{abstract}
Cancer undoubtedly affects patients in all aspects. Cancer diagnosis is a stressful event and coping is the primary mechanism used to adjust and counteract the stress. This study aims to assess the coping styles and prevalence of depression among solid organ cancer patients during treatment phase, attending two tertiary care hospitals of Karachi. A cross-sectional survey was conducted among solid organ cancer patients at Aga Khan University Hospital and Jinnah Post Graduate Medical Center. Coping and depression were assessed by Brief COPE and Self Reporting Questionnaire (SRQ) 20 respectively. Purposive sampling technique was used to recruit 488 patients. Coping styles are reported as mean \pm SD. Prevalence has been computed for depression and Chi-square test is used to assess the relationship of depression with different variables. Correlation was assessed for coping styles and depression. The frequently used coping styles were active coping, acceptance, religion and self-distraction. $48.4 \%$ depression was estimated among patients. The significantly positive correlation of depression was found with active coping, planning, self-blame, venting, use of emotional support and substance use. While depression correlated negatively with acceptance, religion, selfdistraction and humor. Depression was significantly associated with study sites, age, socioeconomic quintiles, past history of hospitalization and substance use. Our research addressed the missing element of mental health in oncology. Depression is a common mental ailment and often the initial manifestation towards deterioration of mental health. Each cancer patient copes differently which either promotes or hinders their fighting spirit. Hence,
\end{abstract}


mental health screening and counseling are recommended in the treatment protocol of cancer patients. Also, support group interventions can help cancer patients to cope effectively.

\section{Keywords}

Coping, Depression, Cancer Patients, Mental Health

\section{Introduction}

Cancer is a fatal illness which affects patients and their families physically, socially, emotionally and mentally. According to global statistics, "there were about 14.1 million new cancer cases, 8.2 million cancer deaths and about 32.6 million people living with cancer in year 2012 worldwide" [1]. Regional statistics from Asia reports that "in the year 2000, there were over 3 million new cancer cases and over 2 million cancer deaths in Asia and projections suggested that the number of new cases will rise up to 7.1 million by year 2020" [2]. No nationally representative statistics is available for Pakistan as no national registry is in place. The number of cancer patients reported by the Aga Khan University Hospital Cancer Registry for the years 2009, 2010 and 2011 was 2128, 2071 and 2172 individuals respectively. Based on the Aga Khan University Hospital Cancer Registry, gastrointestinal, breast, head and neck, lungs and gynecological cancers were predominately reported among cancer patients (Table 1).

Cancer diagnosis for individuals and their families is an agonizing stress. The reaction to cancer diagnosis varies from person to person based upon their coping style. Individual can feel shocked or traumatized as the prospect of an impending death. Others deny the reality and hide cancer's existence, and decide not to go for treatment [3]. In addition, during rigorous treatment, which can

Table 1. Data from the Aga Khan university hospital cancer registry showing number of cancer patients for the year 2009, 2010 and 2011.

\begin{tabular}{cccc}
\hline Cancers & \multicolumn{3}{c}{ Years } \\
\cline { 2 - 4 } Head \& neck & $\mathbf{2 0 0 9}$ & $\mathbf{2 0 1 0}$ & $\mathbf{2 0 1 1}$ \\
Gastro-intestinal & 288 & 265 & 293 \\
Lung & 429 & 494 & 534 \\
Bone \& Soft tissue sarcoma & 134 & 158 & 141 \\
Breast & 84 & 60 & 90 \\
Skin & 492 & 340 & 346 \\
Gynecological & 24 & 26 & 48 \\
Prostate & 183 & 167 & 134 \\
Testis & 96 & 109 & 73 \\
Renal & 17 & 17 & 15 \\
Urinary Bladder & 48 & 54 & 62 \\
Brain tumor & 54 & 62 & 54 \\
\end{tabular}


range from chemotherapy, radiation, surgery or a combination of the three, patients experience many physical and emotional changes, often with lasting consequences on mental health [4]. "There is substantial evidence which suggest that cancer patients suffer from considerable and long-term psychological distress associated with different forms of cancer and its medical treatment" [3].

In order to adapt with the stress, people use various coping strategies. Coping is used as a primary mechanism and is defined as "the cognitive and behavioral efforts made to master, tolerate, or reduce external and internal demands and conflicts among them" [5]. Lazarus and Folkman used a model to describe the coping process [6]. They explained that "an individual first of all appraises the situation faced in the light of their values, beliefs, and intentions; and then considers solutions and resources available, whether consciously or not, and formulates a coping response" [6]. They proposed two modes of coping strategies: problem-focused coping and emotion-focused coping [6].

Problem-focused coping is directed at the stressor itself for instance, taking actions to remove or to escape the stressor, or to lessen its impact if it cannot be escaped. The emotion-focused coping is targeted at minimizing the distress caused by the stressors. It includes a wide range of options ranging from selfsoothing (e.g. relaxation, seeking emotional support), to expression of negative emotion (e.g. yelling, crying), to a focus on negative thoughts (e.g. suicide) in an attempt to escape stressful situations (e.g. avoidance, denial, wishful thinking) [7].

Literature suggests that use of some coping strategies may prove beneficial for the person. A study conducted on medically ill elderly men found a high proportion of men seeking comfort in religious practices and beliefs which was inversely related to their severity of depression [8].

Coping is an important determinant in the process from stressful situations to adaptation outcomes [9]. Limited evidence is available on how solid organ cancer patients cope with their illness specifically during their treatment phase. Also, coping with cancer is an understudied area in Pakistan and effective psychological counseling and interventions do not exist in the usual treatment regime for cancer patients.

Early identification of patients coping poorly is important for timely recognition of mental distress and compliance with the treatment. Mental distress, anxiety and depression can occur at any stage during the illness process and can adversely affect the coping of patient. Although these conditions are common in cancer patients, they are often overlooked and left untreated. Therefore, early recognition and treatment of psychiatric disorders in the process of cancer diagnosis and treatment is imperative. Particularly in life threatening diseases such as cancer, knowledge of coping styles by the treating oncologist has important implications where counseling and referral of patients to mental health professional can be timely indicated to prevent the deterioration in mental health. Understanding of these psychological disorders can help in treatment planning and may result in treatment success. 
Hence, this study aimed to investigate the frequently used coping strategies and prevalence of depression among solid organ cancer patients.

\section{Methods}

The primary objective of this study was to identify and estimate the frequency of different coping styles used by solid organ cancer patients during their treatment phase. The secondary objectives focused on estimating the prevalence of depression along with identifying the associated factors in cancer patient attending two tertiary care hospitals of Karachi, Pakistan.

A cross-sectional survey was conducted in two tertiary care hospitals of Karachi: the Age Khan University Hospital (AKUH) and the Jinnah Post Graduate Medical Center (JPMC). AKUH is a tertiary care, private and non-for-profit hospital which provides comprehensive oncology services for almost all adult and paediatrics cancers including: medical and surgical treatment, radiation and chemotherapy and bone marrow transplant. Majority of the patients coming to AKUH belong to middle and high socioeconomic status. Moreover, the hospital has a welfare department which helps needy and deprived people seeking care at the hospital.

The second site JPMC is a biggest and best equipped public tertiary care hospital in Pakistan rendering quality health care services to the ailing. JPMC has a separate, well-staffed department of clinical oncology where patients are seen and treated in outpatient clinics, daycare oncology unit and inpatient oncology wards. JPMC caters to low to middle income strata of Karachi. Patients are treated on minimal out of pocket payment while financial help is given to all patients.

Based upon the sample size calculation (standard deviation 1.88, Mean difference 0.5 and Level of significance $\alpha=0.05$ ) [8], 488 participants were enrolled in the study. Open Epi version 3.01 and World Health Organization (WHO) calculator for sample size determination were used.

Adult male and female cancer patients with known primary origin of cancer, histologically proven with treatment duration ranging from diagnosis till 3 months for neo-adjuvant treatment and diagnosis till 6 months for adjuvant treatment were eligible for participation. This criterion was important because patients receiving adjuvant treatment have CT-Scan at 6 months following the diagnosis for evaluating the tumor growth while for those receiving neo-adjuvant treatments; the scan is performed at 3 months. CT-Scan has significance because patients get to know about their prognosis, hence leading to positive or negative emotional state. Patients consenting and able to give interview were considered eligible.

In contrast, those patients who had history of psychiatric illness or had used psychotropic medication, along with those who were not on treatment or were diagnosed with blood malignancies, cancer recurrence or were receiving palliative treatment for severe disease or had other serious chronic illness such as $\mathrm{He}$ patitis C, Chronic Liver Disease (CLD), Congestive Cardiac Failure (CCF) or 
Chronic Kidney Disease (CKD) and those who were unable to give interview because of language barrier were excluded.

Pretesting was performed on $10 \%$ of the total sample size. Data was collected over the period of 4 months starting from February till June, 2014.

Non probability purposive sampling technique was used to recruit patients. In AKUH, patients were daily identified through the list generated in the clinics, chemotherapy outpatient unit and radiations unit. List included information about the patient, their medical record number, diagnosis, treating oncologist and current status of treatment. After reviewing the list, eligible patients were approached, informed consent was sought and patients were interviewed. In JPMC, patients were approached directly in the waiting area of the clinics and at the chemotherapy room, as no prior list was available. Patients were coming randomly to visit their physicians and for chemotherapy administration. Upon confirming their histopathology report (biopsy date), written informed consent was sought and interviews were conducted. Patients' medical records were reviewed after completing the interview at both sites. Data collection was carried out by principal investigator (PI) and data collectors. A total of 488 patients were recruited, of them 259 (53\%) were from AKUH and 229 (47\%) from JPMC. We aimed to achieve equal number of participants from both sites in order to have equal representation from private and public sector hospitals. However; the proportion of patients coming to AKUH was more compared to that of JPMC which resulted in slightly higer number of patients from AKUH at the end of 4 months of data collection.

1) Data Collection

A questionnaire was designed that collected information regarding socio demographic and cancer related characteristics such as age, type of family, educational level, occupation, type, stage and treatment of cancer and socioeconomic status. Depression was assessed using Self Reporting Questionnaire (SRQ) 20 and coping styles using Brief COPE scale.

2) Self-Reporting Questionnaire (SRQ 20)

The SRQ 20 screens for depression by using 20 questions. Each of the 20 items is coded as 0 and 1 where 1 indicates the presence of symptom during last one month and 0 indicates the opposite. This scale has been validated in Pakistan [10]. It provides sensitivity of $80 \%$ and specificity of $85.4 \%$ [11]. This scale has been translated in Urdu. The cutoff score used for SRQ-20 was greater than and equal to 8 to classify a person as a case.

3) Brief COPE Scale

Brief COPE scale was used to investigate the coping styles used by cancer patients during the past one month. Brief COPE was developed by Professor Charles S. Carver at the University of Miami and has been widely used in the samples of medical and nursing students, communities affected by a natural disaster, caregivers, and patients [12] [13]. It is the shortened version of the original COPE Inventory and assesses 14 coping types with 28 questions ( 2 questions per type). COPE inventory is a multidimensional coping inventory which was de- 
veloped to assess a broad range of coping strategies [13]. The inventory includes both functional as well as dysfunctional responses with 15 coping styles. The scale is scored in a way that absence of one response does not imply the presence of the opposite because people engage in wide range of coping during a given time period [13]. It has 60 questions which are measured on a 4-point Likert scale [13]. A shorter version of COPE was developed because earlier patient samples became restless due to the long list of questions [14].

Since many of the participants presenting to the hospital were not literate, these items were rephrased in order to make it an interviewer based questionnaire and were translated in Urdu. Author did not attempt to divide this tool into positive or negative coping strategies, but these 14 dimensions are suggestively divided into problem focused (adaptive) and emotion focused (maladaptive) coping by many studies (Figure 1). The responses to these questions were measured on a 4-point Likert scale with options ranging from 1 ("I've not done this at all") to 4 ("I've been doing this a lot"). The scores range from 2 to 8 and the means for each coping style were then calculated.

Data was analyzed using STATA Version 12. Mean and standard deviation (SD) were computed for the quantitative variables whereas frequencies and proportions were calculated for the categorical variables. Chi-Square test was used to assess the relationship between various variables and depression. Moreover; correlation was assessed and reported as Rho and p-value for the 14 coping styles and depression. Correlation was computed using Spearman Rank Correlation. Spearman Rank Correlation is a non-parametric test used to assess the degree of association between two variables. It does not entail any assumptions about the distribution of the data and is the appropriate correlation analysis when the variables are measured on a scale that is at least ordinal. It is calculated using the formula in "Equation (1)".

$$
r_{s}=1-\left(6 \sum d_{i}^{2} / n^{3}-n\right)
$$

Study approval was obtained from the Ethics Review Committee (ERC) of Aga Khan University and the Department of Clinical Oncology at JPMC. A written informed consent was obtained from each participant and a thumb impression was taken from those who were unable to sign.

\begin{tabular}{|c|c|}
\hline Adaptive Coping & Maladaptive Coping \\
\hline Active Coping & \multirow{2}{*}{$\begin{array}{c}\text { Behavioral } \\
\text { Disengagement } \\
\end{array}$} \\
\hline Instrumental Support & \\
\hline Planning & Denial \\
\hline Accentance & Self-Distraction \\
\hline Fmotional Sunnort & Self-Blame \\
\hline Humpr & Substance Use \\
\hline & Venting \\
\hline Positive Reframing & \\
\hline Religion & \\
\hline
\end{tabular}

Figure 1. Suggested distribution of coping styles as problem focused (adaptive) and emotion focused (maladaptive). 


\section{Results}

Table 2 shows the coping styles used by cancer patients during the treatment phase. The frequently used coping styles were active coping (7.11 \pm 0.06$)$, acceptance (6.81 \pm 0.06$)$, religion (6.07 \pm 0.09$)$ and self-distraction (5.87 \pm 0.09$)$. All of these coping styles are problem focused except self-distraction which is an emotion focused coping style. The lowest scores were found on substance use (2.05 \pm $0.01)$, behavioral disengagement $(2.07 \pm 0.02)$ and denial $(2.58 \pm 0.06)$.

Table 3 shows the socio-demographic characteristics of cancer patients. More than $50 \%$ of the sample comprised of women and majority were between the ages of $40-59$ years. Around $84 \%$ of the participants were married and 50\% lived in a nuclear family. For the socioeconomic status, participants were divided into quintiles based upon the factor analysis. The first quintile referred to the poorest class while the fifth represented the richest. Table 3 shows that $33 \%$ of the JPMC patients were under the first quintile indicating a poor strata of the population whereas only $8.5 \%$ of AKUH patients were classified in the first quintile.

Table 4 describes the cancer related characteristics of the patients and prevalence of depression. Overall, $32 \%$ of the sample had breast cancer $(38 \%$ in AKUH and 26\% in JPMC) followed by cancers of head and neck (overall 23\%; $15 \%$ in AKUH and 32\% in JPMC), gastrointestinal (overall 19\%; $21 \%$ in AKUH and $18 \%$ in JPMC) and gynecological sites (overall 12.5\%; $10 \%$ in AKUH and $15 \%$ in JPMC). Majority patients were in stage $3(42 \%)$ at both sites with overall $30 \%$ receiving chemotherapy only and $29 \%$ receiving chemotherapy with surgery. Additionally, one fourth (28\%) of the participants had a family history of cancer. Overall depression was found among $48.4 \%$ of the patients where $60 \%$ of JPMC patients were found depressed compared to $38 \%$ in AKUH.

We also assessed correlation between different coping styles and depression.

Table 2. Coping style scores (mean and SD) in solid organ cancer patients.

\begin{tabular}{ccc}
\hline Brief COPE coping style & Mean \pm SD & Range \\
\hline Active coping & $7.11 \pm 0.06$ & $2-8$ \\
Acceptance & $6.81 \pm 0.06$ & $2-8$ \\
Religion & $6.07 \pm 0.09$ & $2-8$ \\
Self-distract & $5.87 \pm 0.09$ & $2-8$ \\
Positive reframing & $4.98 \pm 0.08$ & $2-8$ \\
Planning & $4.87 \pm 0.09$ & $2-8$ \\
Use instrumental support & $4.80 \pm 0.10$ & $2-8$ \\
Humour & $4.13 \pm 0.06$ & $2-8$ \\
Self-blame & $3.46 \pm 0.09$ & $2-8$ \\
Venting & $3.44 \pm 0.06$ & $2-8$ \\
Use emotional support & $3.18 \pm 0.06$ & $2-8$ \\
Denial & $2.58 \pm 0.06$ & $2-8$ \\
Behavioral disengagement & $2.07 \pm 0.02$ & $2-8$ \\
Substance use & $2.05 \pm 0.01$ & $2-8$ \\
\hline
\end{tabular}


Table 3. Socio demographic characteristics of solid organ cancer patients in two tertiary care hospitals of Karachi $(\mathrm{n}=488)$.

\begin{tabular}{|c|c|c|c|}
\hline \multirow{2}{*}{ Variables } & \multirow{2}{*}{$\mathrm{n}(\%)$} & \multicolumn{2}{|c|}{ Study sites } \\
\hline & & AKUH $(n=259)$ n (\%) & JPMC $(n=229) n(\%)$ \\
\hline \multicolumn{4}{|l|}{ Age (years completed) } \\
\hline $18-29$ & $46(9.4)$ & $14(5.4)$ & $32(14.0)$ \\
\hline $30-39$ & $82(16.8)$ & $41(16.0)$ & $41(18.0)$ \\
\hline $40-49$ & $124(25.4)$ & $57(22.0)$ & $67(29.0)$ \\
\hline $50-59$ & $127(26.0)$ & $82(31.6)$ & $45(19.6)$ \\
\hline 60 years $\&$ above & $109(22.3)$ & $65(25.0)$ & $44(19.0)$ \\
\hline \multicolumn{4}{|l|}{ Gender } \\
\hline Males & $198(40.6)$ & $107(41.3)$ & $91(39.7)$ \\
\hline Females & $290(59.4)$ & $152(58.7)$ & $138(60.3)$ \\
\hline \multicolumn{4}{|l|}{ Marital status } \\
\hline Married & $408(83.6)$ & $228(88)$ & $180(78.6)$ \\
\hline Never married & $46(9.4)$ & $25(9.7)$ & $21(9.2)$ \\
\hline Widowed/separated/divorced & $34(7.0)$ & $6(2.3)$ & $28(12.2)$ \\
\hline \multicolumn{4}{|l|}{ Socioeconomic quintiles } \\
\hline Lowest quintile & $97(19.9)$ & $22(8.5)$ & $75(33.0)$ \\
\hline 2nd quintile & $98(20.1)$ & $41(15.8)$ & $57(25.0)$ \\
\hline 3rd quintile & $98(20.1)$ & $56(21.6)$ & $42(18.3)$ \\
\hline 4th quintile & $98(20.1)$ & $75(29.0)$ & $23(10.0)$ \\
\hline Highest quintile & $97(19.9)$ & $65(25.1)$ & $32(14.0)$ \\
\hline \multicolumn{4}{|l|}{ Family type } \\
\hline Nuclear & $247(50.6)$ & $127(49.0)$ & $120(52.4)$ \\
\hline Extended & $241(49.4)$ & $132(51.0)$ & $109(47.6)$ \\
\hline
\end{tabular}

Table 5 shows that depression was significantly positively correlated with active coping (p-value $<0.001$ ), planning (p-value $<0.001$ ), self-blame (p-value $<$ 0.001 ), venting ( $\mathrm{p}$-value $<0.001$ ), use emotional support ( $\mathrm{p}$-value 0.0405 ) and substance use ( $\mathrm{p}$-value $<0.001)$. There was a significantly negative correlation between depression and acceptance ( $\mathrm{p}$-value $<0.001$ ), religion ( $\mathrm{p}$-value 0.0404), self-distraction ( $\mathrm{p}$-value $<0.001$ ) and humor ( $\mathrm{p}$-value $<0.001$ ).

We determined the relationship between depression and different variables. Table 6 shows that the relationship between depression and study sites was significant, where patients from JPMC were more likely to be depressed as compared to AKUH. Secondly, age was significantly associated with depression, where participants aged $30-39$ years and $40-49$ were more likely to be depressed as compared to the other age categories.

Although females were found to be more depressed compared to men, the relationship was not statistically significant. Similarly the relationship between the sites of cancer and depression was not significant, though depression was found more prevalent among patients with lung, brain, thymoma, eye and skin cancers. The relationship between socioeconomic quintiles and depression was significant where the lowest wealth quintile accounted for more depressed participants compared to the other 4 quintiles. Likewise, the relationship between substance use and depression was found to be significant where the current users were more likely to be depressed compared to past or non-users. The relationship was also significant for patients with past history of hospitalization. 
Table 4. Cancer related characteristics and prevalence of depression in solid organ cancer patients in two tertiary care hospitals of Karachi $(n=488)$.

\begin{tabular}{|c|c|c|c|}
\hline \multirow{2}{*}{ Variables } & \multirow{2}{*}{$\mathrm{n}(\%)$} & \multicolumn{2}{|c|}{ Study sites } \\
\hline & & AKUH $n=259 n(\%)$ & $J P M C n=229 n(\%)$ \\
\hline \multicolumn{4}{|l|}{ Site of cancer } \\
\hline Breast & $158(32.4)$ & $98(38.0)$ & $60(26.2)$ \\
\hline Head and neck & $114(23.4)$ & $40(15.4)$ & $74(32.3)$ \\
\hline Gastrointestinal & $96(19.7)$ & $55(21.2)$ & $41(18.0)$ \\
\hline Gynecological & $61(12.5)$ & $27(10.4)$ & $34(14.8)$ \\
\hline Genitourinary & $23(4.7)$ & $18(7.0)$ & $5(2.2)$ \\
\hline Sarcoma & $13(2.7)$ & $10(3.8)$ & $3(1.3)$ \\
\hline Lung & $12(2.5)$ & $6(2.3)$ & $6(2.6)$ \\
\hline Others (brain, thymoma, skin \& eye) & $11(2.2)$ & $5(1.9)$ & $6(2.6)$ \\
\hline \multicolumn{4}{|l|}{ Stage of cancer } \\
\hline I & $37(7.6)$ & $24(9.3)$ & $13(5.7)$ \\
\hline II & $122(25)$ & $73(28.2)$ & $49(21.4)$ \\
\hline III & $207(42.4)$ & $105(40.5)$ & $102(44.5)$ \\
\hline IV & $104(21.3)$ & $53(20.5)$ & $51(22.3)$ \\
\hline Unknown & $18(3.7)$ & $4(1.5)$ & $14(6.1)$ \\
\hline \multicolumn{4}{|l|}{ Treatment of cancer } \\
\hline Chemotherapy & $146(30)$ & $68(26.2)$ & $78(34.1)$ \\
\hline Surgery & $84(17.2)$ & $45(17.4)$ & $39(17.0)$ \\
\hline Radiations & $24(4.9)$ & $5(2.0)$ & $19(8.3)$ \\
\hline Chemotherapy and surgery & $141(28.9)$ & $94(36.3)$ & $47(20.5)$ \\
\hline Chemotherapy and radiations & $27(5.5)$ & $7(2.7)$ & $20(8.7)$ \\
\hline Radiations and surgery & $24(4.9)$ & $15(5.8)$ & $9(4.0)$ \\
\hline Chemotherapy, radiations and surgery & $42(8.6)$ & $25(9.6)$ & $17(7.4)$ \\
\hline \multicolumn{4}{|l|}{ Family history of cancer } \\
\hline Yes & $135(27.7)$ & $85(32.8)$ & $50(21.8)$ \\
\hline No & $353(72.3)$ & $174(67.2)$ & $179(78.2)$ \\
\hline \multicolumn{4}{|l|}{ Depression status } \\
\hline Depressed & $236(48.4)$ & $99(38.2)$ & $137(59.8)$ \\
\hline Not depressed & $252(51.6)$ & $160(61.8)$ & $92(40.2)$ \\
\hline
\end{tabular}

Table 5. Correlation between (Brief COPE) coping styles and depression.

\begin{tabular}{ccc}
\hline Brief COPE coping style & Spearman correlation (Rho) & p-value \\
\hline Active coping & 0.2250 & $<0.001^{\star}$ \\
Acceptance & -0.1693 & $<0.001^{\star}$ \\
Religion & -0.0928 & $0.04^{\star}$ \\
Self-distract & -0.3186 & $<0.001^{\star}$ \\
Positive reframing & 0.0097 & 0.83 \\
Planning & 0.1530 & $<0.001^{\star}$ \\
Use instrumental support & -0.0267 & 0.56 \\
Humour & -0.3116 & $<0.001^{\star}$ \\
Self-blame & 0.3141 & $<0.001^{\star}$ \\
Venting & 0.3139 & $<0.001^{\star}$ \\
Use emotional support & 0.0928 & $0.04^{\star}$ \\
Denial & 0.0586 & 0.20 \\
Behavioral disengagement & 0.0673 & 0.14 \\
Substance use & 0.1496 & $<0.001^{\star}$ \\
\hline
\end{tabular}


Table 6. Relationship between depression and different factors of solid organ cancer patients $(\mathrm{n}=488)$.

\begin{tabular}{|c|c|c|c|c|c|}
\hline Variable & Frequency & $\mathbf{N}$ & $\%$ & $\chi^{2}$ & p-value \\
\hline \multicolumn{6}{|l|}{ Study Site } \\
\hline AKUH & 99 & 259 & 38.2 & 22.7 & $<0.001^{*}$ \\
\hline JPMC & 137 & 229 & 60 & & \\
\hline \multicolumn{6}{|l|}{ Sex } \\
\hline Males & 87 & 198 & 44 & 2.6 & 0.106 \\
\hline Females & 149 & 290 & 51 & & \\
\hline \multicolumn{6}{|l|}{ Age (years completed) } \\
\hline $18-29$ & 21 & 46 & 46 & \multirow{5}{*}{11.56} & \multirow{5}{*}{$0.021^{*}$} \\
\hline $30-39$ & 43 & 82 & 52 & & \\
\hline $40-49$ & 74 & 124 & 60 & & \\
\hline $50-59$ & 54 & 127 & 42 & & \\
\hline 60 years $\&$ above & 44 & 109 & 40 & & \\
\hline \multicolumn{6}{|l|}{ Marital status } \\
\hline Never married & 17 & 46 & 37 & \multirow{3}{*}{3.91} & \multirow{3}{*}{0.141} \\
\hline Married & 199 & 408 & 49 & & \\
\hline Widowed/divorced & 20 & 34 & 59 & & \\
\hline \multicolumn{6}{|l|}{ Site of cancer } \\
\hline Head and neck & 62 & 114 & 54 & \multirow{8}{*}{9.36} & \multirow{8}{*}{0.227} \\
\hline Breast & 76 & 158 & 48 & & \\
\hline Gynecological & 27 & 61 & 44 & & \\
\hline Gastrointestinal & 45 & 96 & 47 & & \\
\hline Genitourinary & 7 & 23 & 30 & & \\
\hline Lungs & 8 & 12 & 67 & & \\
\hline Sarcoma & 4 & 13 & 31 & & \\
\hline Others (eye, skin \& thymoma) & 7 & 11 & 64 & & \\
\hline \multicolumn{6}{|l|}{ Cancer stage } \\
\hline I & 16 & 37 & 43 & \multirow{5}{*}{4.13} & \multirow{5}{*}{0.388} \\
\hline II & 56 & 122 & 46 & & \\
\hline III & 97 & 207 & 47 & & \\
\hline IV & 55 & 104 & 53 & & \\
\hline Unknown & 12 & 18 & 67 & & \\
\hline \multicolumn{6}{|l|}{ Socioeconomic quintiles } \\
\hline Lowest quintile & 61 & 97 & 63 & \multirow{5}{*}{19.54} & \multirow{5}{*}{$0.001^{*}$} \\
\hline 2nd quintile & 54 & 98 & 55 & & \\
\hline 3rd quintile & 40 & 98 & 41 & & \\
\hline 4th quintile & 34 & 98 & 38 & & \\
\hline Highest quintile & 47 & 97 & 48 & & \\
\hline \multicolumn{6}{|l|}{ Substance users } \\
\hline Current users & 79 & 125 & 63 & \multirow{3}{*}{14.85} & \multirow{3}{*}{$0.001^{\star}$} \\
\hline Past users & 34 & 77 & 44 & & \\
\hline Non-users & 123 & 286 & 43 & & \\
\hline Past hospitalization & & & & & \\
\hline Yes & 80 & 193 & 41 & 6.10 & $0.013^{*}$ \\
\hline No & 156 & 295 & 53 & & \\
\hline Cancer treatment & & & & & \\
\hline Chemotherapy & 71 & 146 & 49 & & \\
\hline Radiations & 15 & 24 & 62 & & \\
\hline Surgery & 36 & 84 & 43 & & \\
\hline Chemotherapy \& radiation & 13 & 27 & 48 & 3.68 & 0.720 \\
\hline Chemotherapy \& surgery & 66 & 141 & 47 & & \\
\hline Radiations \& surgery & 13 & 24 & 54 & & \\
\hline Chemotherapy, radiation and surgery & 22 & 42 & 52 & & \\
\hline
\end{tabular}

${ }^{*}$ p-value $<0.05$. 


\section{Discussion}

Cancer is a life threatening disease which is not only known for high mortality but also for its enduring adverse effects on life and mental health. Due to the burden of cancer, as much as $70 \%$ of the precious Years of Life are Lost (YLLs) [3]. People react in different ways to the news of being diagnosed with cancer and they adopt different coping strategies to counteract the stress.

Our study evaluated the coping styles that solid organ cancer patients frequently used during their treatment phase and also determined the prevalence of depression.

The frequently used coping styles found in this study were active coping, acceptance, religion and self-distraction. The finding of our study is to an extent consistent with another study that has assessed the coping styles of depressed patients where the frequently used coping strategies were religion 5.46 (1.84), acceptance 4.73 (1.59), use of instrumental support 4.71 (1.38), use of emotional support 4.63 (1.88) and self-distraction 4.56 (1.41) [8]. Their mean coping scores were lower compared to that found in our study. The possible reason of cancer patients scoring high on coping styles can be attributed to the grave nature of illness, where in order to adapt and adjust with the stress; patients used greater aspect of their coping styles.

Similarly, a study done by Elsheshtawy and his colleagues showed that the frequently used coping styles by Egyptian breast cancer patients were religion $(4.55 \pm 1.6)$, acceptance $(4.14 \pm 1.3)$, emotional support $(4.04 \pm 1.4)$ and selfdistraction $(3.62 \pm 1.3)$.

It was interesting to note that in the wake of life threatening illness; acceptance and religion were the most commonly used coping strategies in our study as well as in other studies. In contrast, in each of these studies the least frequently used styles were substance use, behavioral disengagement, self-blame, humor and denial.

Inclination towards religion is usually associated with the feeling of acceptance and an enhanced ability to cope effectively which in turn reduces engagement in self-harming behaviors. Likewise an inverse relation between religion and substance use and a direct relation between religion, acceptance and active coping was observed in our study.

Of the frequently used coping styles, active coping was the top most used followed by acceptance, religion and self-distraction.

Active coping is a problem focused coping style which involves the use of those psychological or behavioral coping efforts in which the person use one's own resources to deal with a stressful situation in order to alter the nature of stressor or to modify the reactions towards it [15]. In our study active coping was the frequently used style but at the same time it was surprising to know that it correlated positively with depression. An inverse correlation between depression and active coping could be attributed to the cancer stage. Most of the patients were in stage 3 of cancer and were actively seeking solutions to deal with the stress but in the process of dealing actively they might have faced the painful 
reality about their prognosis. Stage 3 cancers are advance stage cancers compared to stage 1 and 2. Moreover the side effects of chemotherapy may potentially be the cause of depression since advanced stages of cancer require rigorous treatment in the form of chemotherapy.

Religion is seen as one of the strong coping style used by patients during their illness. Though it is considered as an adaptive coping strategy, its actual role is more towards the emotional wellbeing and regulation. Patients using religion as their most important and frequent style presume and accept that the disease is from the Almighty and they have to accept the path which is chosen for them by their God. This is the reason "acceptance" along with the religion is also among the frequently used coping style found in our study.

Active coping, acceptance and religion are the problem focused coping style, while self-distraction which is an emotion focused coping style was also frequently used by cancer patients in our study. Self-distraction actually works by interrupting the mood and shifting the gear. When a person ruminate over the problem which is out of his control, he will worry over it again and again whereas the distraction will break the cycle by forcing the person to engage his acts and thinking in something more interesting. This temporarily stops the process of rumination and the person feels better for a certain period of time. Selfdistraction plays a role in emotion regulation.

Furthermore, our study identified the prevalence of depression among solid organ cancer patients. A total of $48.4 \%$ of the sample was found positive for the depression. Diagnosis of cancer can have a noticeable impact on most patients. Fear, anxiety and depression are very common expected responses to the brutal life changing experience [16]. The finding of this study indicated that almost half sample was depressed during the disease and treatment period. The prevalence of depression among cancer patients found by other studies conducted in Karachi was $36 \%$ and $52 \%$ [3] [17].

Literature highlights that the use of more passive and less active coping strategies is usually associated with higher levels of depressive symptoms in patients having various chronic illnesses such as HIV and breast cancer [15]. However, in this study most of the patients used active coping and religion as their coping strategies.

We also found significant relationship of depression with age, where patients between the ages of 30 - 49 years were found more depressed. Depression was significantly associated with study sites, socioeconomic quintiles, history of past hospitalization and use of substances.

Our study revealed several important coping styles frequently used by cancer patients during their treatment phase. Patients mostly used problem focused coping styles while the emotion focused coping styles such as substance use, denial, self-blame were less frequently used.

This study highlighted important findings related to the response of patients towards the unwanted change in their lives. The care cancer patients receive from the day of diagnosis lacks the important element of psychological health. The concept of psycho-oncology has not been implemented yet in almost every 
cancer health facility in Pakistan. Knowledge of coping and psychological health should be considered an important part of treatment process and the treating oncologist should be aware of it. Cancer is always considered a biggest stressor for each and every person. Timely identification of psychological distress by the treating oncologist will limit the progression of mental diseases as well as will help patients to vent their feelings associated with their disease and treatment.

Moreover formulation of cancer support groups in which different cancer patients can meet with the survivors and other patients with similar cancer origin will also help them feel positive and motivated. There is considerable evidence on the benefits from social groups to the cancer patients [14]. Reviews of research into various types of support groups; cancer self-help groups, non-directive, professionally led groups, and directive group interventions have showed improvement in quality of life, coping, affect and possibly survival among cancer patients [14]. Fellow patients can also prove as positive role models. They can share understanding and information on coping not available from family, friends and health professionals [14].

The strengths of this study are; first of all, this study has large sample size. Previously qualitative studies have been conducted on coping whereas limited quantitative evidences are available in the context of Pakistan. Our study is among the few researches that have quantitatively assessed coping among Pakistani solid organ cancer patients. Our study assessed coping at one instance during the treatment phase, however in order to better assess coping, several assessments at different time points can be made. This study is a cross sectional survey, hence temporality cannot be established. Also, the outcome and depression were measured by self reports which can be improved by including psychiatrist in the assessment phase for more sensitive assessment.

\section{Conclusion}

Cancer patients undergoing treatment experience high level of distress. However coping is the way patients use to respond to the stress. Helping patients to cope adaptively will help them feel positive throughout the painful journey. Depression and other psychological disorders are very common among cancer patients and many patients develop these disorders during the course of illness. Interventions to address psychological needs of the patient during illness and treatment phase should be the prime responsibility of treating oncologist. It is recommended that patients should be assessed for coping at different instances during the treatment process to identify the alterations in psychological health in the form of fear, anxiety or depression. It is necessary to plan and implement psychological interventions in the most vulnerable phase of patient's disease. Creating cancer support groups could help patients cope effectively and positively influencing their compliance with the treatment and survival.

\section{Acknowledgements}

This study is funded by Department of Community Health Sciences as part of 
Master's Thesis. This support is highly appreciated.

\section{References}

[1] International Agency for Research on C. GLOBOCAN 2012: Estimated Cancer Incidence, Mortality and Prevalence Worldwide in 2012. World Health Organization. http://globocan.iarc.fr/Pages/fact_sheets_cancer.aspx

[2] Hanif, M., Zaidi, P., Kamal, S. and Hameed, A. (2009) Institution-Based Cancer Incidence in Alocal Population in Pakistan: Nine Year Data Analysis. Asian Pacific Journal of Cancer Prevention, 10, 227-230.

http://www.apocpcontrol.com/paper_file/issue_abs/Volume10_No2/227c\%20Hanif. pdf

[3] Rashid, Y.A., Ghafoor, Z.A., Masood, N., Mehmood, T., Awan, S., Ansar, T., et al. (2012) Psychosocial Impact of Cancer on Adult Patients. The Journal of the Pakistan Medical Association, 62, 905-909.

[4] Chen, P.Y. and Chang, H.-C. (2012) The Coping Process of Patients with Cancer. European Journal of Oncology Nursing, 16, 10-16.

http://ac.els-cdn.com/S1462388911000068/1-s2.0-S1462388911000068-main.pdf?_ti $\mathrm{d}=52330 \mathrm{a} 78-\mathrm{d} 715-11 \mathrm{e} 6-810 \mathrm{a}-00000 \mathrm{aacb} 35 \mathrm{e} \& \mathrm{acdnat}=1484039905 \_57 \mathrm{ba7caef3be1c2}$ 1bb4924752672b55a

https://doi.org/10.1016/j.ejon.2011.01.002

[5] Krohne, H.W. (2001) Stress and Coping Theories. The International Encyclopedia of the Social and Behavioral Sciences, 22, 15163-15170. https://doi.org/10.1016/B0-08-043076-7/03817-1

[6] Cooper, C., Katona, C., et al. (2008) Validity and Reliability of the Brief COPE in Carers of People with Dementia: The LASER-AD Study. The Journal of Nervous and Mental Disease, 196, 838-843. https://doi.org/10.1097/NMD.0b013e31818b504c

[7] Carver, C.S. and Connor-Smith, J. (2010) Personality and Coping. Annual Review of Psychology, 61, 679-704.

http://www.annualreviews.org/doi/pdf/10.1146/annurev.psych.093008.100352 https://doi.org/10.1146/annurev.psych.093008.100352

[8] Kasi, P.M., Naqvi, H.A., Afghan, A.K., Khawar, T., Khan, F.H., Khan, U.Z., et al. (2012) Coping Styles in Patients with Anxiety and Depression. ISRN Psychiatry, 2012, Article ID: 128672. https://doi.org/10.5402/2012/128672

[9] Elsheshtawy, E.A., Abo-Elez, W.F., Ashour, H.S. and Farouk, O. (2014) Coping Strategies in Egyptian Ladies with Breast Cancer. Breast Cancer. Basic and Clinical Research, 8, 97.

[10] Harpham, T., Reichenheim, M., et al. (2003) Measuring Mental Health in a CostEffective Manner. Health Policy and Planning, 18, 344-349.

https://doi.org/10.1093/heapol/czg041

[11] Sattar, A., Salih, M., et al. (2010) Burden of Common Mental Disorders in Patients with Functional Dyspepsia. JPMA-Journal of the Pakistan Medical Association, 60, 995.

[12] Valvano, A. and Stepleman, L. (2013) Critical Synthesis Package: Brief COPE Questionnaire. MedEdPORTAL Publications, 9, 9453.

https://doi.org/10.15766/mep_2374-8265.9453

[13] Carver, C.S. (1997) You Want to Measure Coping But Your Protocol Is Too Long: Consider the Brief Cope. International Journal of Behavioral Medicine, 4, 92-100. https://doi.org/10.1207/s15327558ijbm0401_6

[14] Grande, G.E., Myers, L.B. and Sutton, S.R. (2006) How Do Patients Who Participate 
in Cancer Support Groups Differ from Those Who Do Not? Psycho-Oncology, 15, 321-334. https://doi.org/10.1002/pon.956

[15] Bardwell, W.A., Ancoli-Israel, S. and Dimsdale, J.E. (2001) Types of Coping Strategies Are Associated with Increased Depressive Symptoms in Patients with Obstructive Sleep Apnea. Sleep: Journal of Sleep and Sleep Disorders Research, 24, 905-909.

[16] American Cancer Society (2016) Anxiety, Fear and Depression. http://www.cancer.org/acs/groups/cid/documents/webcontent/002816-pdf.pdf

[17] Dogar, I.A., Azeem, M.W., Kiran, M., Hussain, I., Mehmood, K. and Hina, I. (2009) Depression and Anxiety in Cancer Patients in Outpatient Department of a Tertiary Care Hospital in Pakistan. Pakistan Journal of Medical Sciences, 25, 734-737.

Submit or recommend next manuscript to SCIRP and we will provide best service for you:

Accepting pre-submission inquiries through Email, Facebook, LinkedIn, Twitter, etc. A wide selection of journals (inclusive of 9 subjects, more than 200 journals)

Providing 24-hour high-quality service

User-friendly online submission system

Fair and swift peer-review system

Efficient typesetting and proofreading procedure

Display of the result of downloads and visits, as well as the number of cited articles

Maximum dissemination of your research work

Submit your manuscript at: http://papersubmission.scirp.org/

Or contact ojepi@scirp.org 